\title{
AVALIANDO JULGAMENTOS NÃO VERBAIS DE IGUALDADE/DIFERENÇA ENTRE ESTÍMULOS AUDITIVOS EM INDIVÍDUOS COM DEFICIÊNCIAS INTELECTUAIS: UMA INVESTIGAÇÃO METODOLÓGICA
}

\author{
ASSESSING NONVERBAL SAME/DIFFERENT JUDGMENTS OF AUDITORY STIMULI IN \\ INDIVIDUALS WITH INTELLECTUAL DISABILITIES: \\ A METHODOLOGICAL INVESTIGATION
}

\author{
RichaRd W. SERNA ${ }^{1}$ \\ UNIVERSITY OF MASSACHUSETTS LOWELL
}

\author{
Mark A. Preston, \& G. Brooks Thompson ${ }^{2}$ \\ UNIVERSITY OF MASSACHUSETTS MEDICAL SCHOOL ${ }^{3}$
}

\begin{abstract}
RESUMO
O presente artigo metodológico relata uma tentativa inicial de avaliar a viabilidade e a utilidade de uma tarefa não verbal para avaliar o julgamento generalizado de igualdade/diferença entre estímulos auditivos em indivíduos com deficiências intelectuais. O Estudo 1 investigou se os participantes poderiam prontamente adquirir uma linha de base de desempenho discriminativo de igualdade/ diferença, em tarefa de "go-left/go-right" (responder à esquerda/responder à direita) com ajuda mínima. Os estímulos-modelo consistiam em pares de sons de frequência única apresentados sucessivamente. Se os sons fossem idênticos, seleções de um estímulo visual no lado esquerdo da tela do computador eram reforçadas. Se os sons fossem diferentes, seleções de um estímulo visual no lado direito da tela do computador eram reforçadas. Dois dos cinco participantes aprenderam prontamente a tarefa, generalizaram o desempenho para outros estímulos e completaram um protocolo rudimentar para avaliar discriminações auditivas que são potencialmente mais dificeis do que aquelas usadas para estabelecer a tarefa inicial. No Estudo 2, dois participantes que não puderam desempenhar a tarefa "go-left/go-right" com os sons de única frequência, mas puderam fazê-lo com palavras faladas como estímulos, transferiram com sucesso o controle das palavras faladas para os sons via um procedimento de esmaecimento e sobreposição de estímulos auditivos. Os achados apoiam a viabilidade de se usar a tarefa como uma avaliação de discriminação auditiva em geral.
\end{abstract}

Palavras-chave: discriminação auditiva, procedimento de resposta à esquerda/resposta à direita, deficiência intelectual, emparelhamento ao modelo, sobreposição e esmaecimento.

\begin{abstract}
This methodological paper reports an initial attempt to evaluate the feasibility and utility of a nonverbal task for assessing generalized same/different judgments of auditory stimuli in individuals with intellectual disabilities. Study 1 asked whether participants could readily acquire a baseline of auditory same/different, go-left/go-right performance with minimal prompting. Sample stimuli consisted of pairs of successively presented sine-wave tones. If the tones were identical, selections of a visual stimulus on the left side of the computer screen were reinforced. If the tones were different, selections of a visual stimulus on the right side of the computer screen were reinforced. Two of five participants readily acquired the task, generalized performance to other stimuli, and completed a rudimentary protocol for examining auditory discriminations that are potentially more difficult than those used to establish the initial task. In Study 2, two participants who could not perform the "go-left/go-right" task with tone stimuli, but could do so with spoken-word stimuli, successfully transferred control by spoken words to tones via an auditory superimposition-and-fading procedure. The findings support the feasibility of using the task as a general-purpose auditory discrimination assessment.
\end{abstract}

Keywords: auditory discrimination, go-left/go-right, intellectual disabilities, matching to sample, superimposition and fading.

\footnotetext{
${ }^{1}$ Corresponding author: Richard W. Serna, PhD. University of Massachusetts Lowell, Psychology Department, Mahoney Hall, 870 Broadway Street, Lowell, MA 01854.Phone: 781-642-0027.E-mail: Richard.Serna@umassmed.edu

${ }^{2}$ Author notes:This research was supported by a grant from the Eunice Kennedy Shriver National Institute of Child Health and Human Development to the University of Massachusetts Medical School, Shriver Center, HD25995.
}

3 University of Massachusetts Medical School, Shriver Center. United States of America. 
Limited and defective auditory learning skills are widely reported in individuals with intellectual disabilities (Abbeduto, Furman, \& Davies, 1989; Chapman, Schwartz, \& Kay-Raining Bird, 1991; Miller, 1987), particularly in those who also have autism (Klinger, Dawson, \& Renner, 2002). These problems impose limitations on a wide range of learning opportunities, including communication, social skills training, and academic instruction. Such opportunities are often the primary focus of intervention programs, for instance those based on the principles of applied behavior analysis (ABA). Children who fail to discriminate spoken words lack critical prerequisites for acquiring effective listening and speaking repertoires. Language training, whether vocal or alternative/augmentative, cannot succeed unless the child distinguishes one word from another. Indeed, Barker-Collo, Jamieson, and Boo (1995) and Vause, Martin, and Yu (2000) have shown that auditory discrimination performance highly correlates with communication ability in individuals with moderate to profound intellectual disabilities.

From a behavior analytic perspective, auditory learning problems can be characterized as a failure of auditory stimulus control, that is, failure to discriminate one auditory stimulus from another. Though establishing auditory stimulus control has been addressed intermittently for many years (Green, 1990; McIlvane \& Stoddard, 1981, 1985; Meyerson \& Kerr, 1977; Schreibman, Charlop, \& Koegel, 1982; Schreibman, Kohlenberg, \& Britten, 1986; Serna, Stoddard, \& McIlvane, 1992; Stoddard, 1982; Stoddard \& McIlvane, 1989), universal success in establishing auditory discrimination has been elusive, par- ticularly for individuals whose intellectual functioning is very low. One reason may be that the auditory stimuli used in many of these studies are spoken words which, given their many prosodic features (e.g., pitch, duration, rise and fall, rhythm, etc.), are relatively complex stimuli. As is known from studies of restricted stimulus control (e.g., "stimulus overselectivity", Dube et al., 2003) and feature classes of visual stimuli (e.g., Serna, Wilkinson, \& McIlvane, 1998), individuals with intellectual disabilities may develop control by only a single aspect of a stimulus, producing stimulus control that is incompatible with the control intended by the experimenter or teacher (stimulus control topography coherence theory; Mcllvane \& Dube, 2003; Mcllvane, Serna, Dube, \& Stromer, 2000). For example, "high functioning" individuals with autism show superior pitch discrimination compared to typically developing individuals (Bonnel et al., 2003). This ability might result in stimulus control that is overly restricted to the pitch dimension of spoken words.

In order to begin to address problems of auditory stimulus control in individuals with intellectual disabilities, a reliable method for assessing current auditory discrimination abilities is needed. Often auditory assessment studies with verbally capable individuals (e.g., Bonnel et al., 2003; Jones et al., 2009; Moore, 1973; Serna, Jeffery, \& Stoddard, 1996) use extensive verbal instructions to establish the task. Sometimes, participants are also instructed to provide their responses vocally. Unfortunately, the language requirements of such tasks preclude their direct use with individuals who have limited or no verbal skills, a population that would es- 
pecially benefit from such an assessment. In order to arrange an auditory discrimination assessment for individuals with intellectual disabilities including limited language skills, a method must not rely on verbal instruction or a verbal response.

In stimulus control terms, such an auditory discrimination assessment task would be an auditory version of generalized conditional stimulus-stimulus relational performance. Such a method might beg in by training a simple auditory discrimination. Once this initial baseline performance is established, a subsequent auditory discrimination would be based on the relation of sameness or difference between two rapidly presented auditory stimuli. For example, the go/no-go task might be used (e.g., D'Amato \& Colombo, 1985): If the stimuli are the same, the participant would respond; if the stimuli are different, the participant would refrain from responding. This task has been used, in fact, to train auditory discrimination in individuals with intellectual disabilities. For example, Serna et al. (1992) showed that two individuals with severe intellectual disabilities could learn the task when the S+ (the "go" stimulus) was the word "touch" and the S(the "no-go" stimulus) was the word "wait." However, unpublished subsequent tests of this go/no-go task yielded far less successful results for several additional participants with severe intellectual disabilities, despite the use of stimulus-control shaping and prompting procedures (see Mcllvane \& Dube, 1992, for a discussion of stimulus-control shaping). The primary pattern of responding for these additional participants was a tendency to respond regardless of whether the S+ or S- was present; refraining from responding was diffi- cult for them. Capitalizing on this propensity of individuals with intellectual disabilities to respond in the presence of auditory stimuli, Serna et al. (1996) successfully established auditory discrimination of two digitized spoken words with a "go-left/go-right" (yes/no) procedure (e.g., D'Amato \& Worsham, 1974), in which a response is required on every trial: If Word 1 was presented, the participant would respond to a visual stimulus on the lower-left side of a computer screen; If Word 2 was presented, the participant would respond to the right. The Serna et al. (1996) study suggests that an adaptation of this "go-left/go-right" task might be used with pairs of successively presented auditory stimuli to establish a "same/different" discrimination.

The present paper evaluates the feasibility and utility of a nonverbal task for assessing generalized same/different judgments of auditory stimuli. Participants were individuals with moderate intellectual disabilities. More specifically, the first of two studies asked whether the "go-left/go-right" task could be adapted to an extent that participants would respond to one side of a computer screen if two successively presented auditory stimuli were identical and to the other side of the screen if the stimuli were not identical. If such performance could be established, the question then became: would it generalize to new auditory stimuli? The first study also explored a rudimentary protocol for examining the development of auditory discriminations that are more difficult than those used in the initial task. A second, follow-up study examined a stimulus-control shaping procedure for transferring the "go-left/go-right" stimulus control from one auditory 
stimulus category (digitized spoken words) to another (tones). Importantly, the present studies represent the beginning of a larger programmatic effort to explore the discrimination of individual features (e.g., pitch, duration, etc.) of auditory stimuli.

\section{GenerAL METHOD}

\section{Apparatus, stimuli, and setting}

Experimental sessions were controlled by custom in-house software (MTS: Dube, 1991; Dube \& Hiris, 1999) running on a Macintosh desktop computer fitted with a touch-sensitive monitor or equipped with a mouse. All stimulus presentations, response consequences, and shaping procedures were fully automated, and responses to the touch-screen monitor were recorded to disk. Two types of auditory stimuli were used: sine-wave tones and recorded spoken words. Pure-tone auditory stimuli were constructed using SoundEdit-16 ${ }^{\circledR}$ software (Macromedia) on a Macintosh computer. Spoken-word stimuli were recorded by a male voice speaking into a digital audio workstation. The specific tone frequencies and words, and their durations, varied according to details of the study (see below). All stimuli were created and presented as 16-bit, 44.1-khz, “.snd” type files. Auditory stimuli were presented via two external speakers placed to the left and right of the computer monitor, or through stereo headphones. All auditory stimuli were presented at a comfortable volume, as determined by the experimenter and participant in an initial volume test. All experimental sessions were conducted in a quiet room away from the participants' classrooms. An experimen- ter, seated behind and to the participant's right, monitored all sessions, initiated trials, and delivered reinforcers.

\section{Procedure}

Auditory discrimination was assessed with a same/different, "go-left/go-right" task. The task is illustrated in Figure 1. Each trial began with the presentation of two auditory stimuli, presented sequentially with a $500 \mathrm{~ms}$ interval separating them, and a white square displayed in the center of the screen. The two stimuli were either identical or different in frequency, and the pair of stimuli repeated every $1200 \mathrm{~ms}$ throughout the trial. The white square served as an observing stimulus; responses to it became effective only after the pair of auditory stimuli had been presented once. When the participant then responded to the observing stimulus (upper left and right portions of Figure 1), two additional squares (hereafter referred to as "keys"), each with a distinct non-representational form, were displayed (lower portion of Figure 1). One key was located in the lower left corner and the other in the lower right corner of the screen. A response to left key was always correct if the two stimuli had the same frequency, and a response to the right key was always correct if the two stimuli had different frequencies. Key locations and their respective forms were the same across all trials and throughout the study.

Correct responses were followed by a 1-sec flashing visual display, a series of melodic tones, and the delivery of a token. Incorrect responses resulted in a blank screen and an intertrial interval (ITI) ranging from 3 to $5 \mathrm{~s}$ during which the screen was blank. The experimenter initiated all trials with a press 
to a keyboard spacebar; trials were initiated only after the participant had finished placing their token from the past trial in a small receptacle to the side of the computer screen.

Trials were presented in a random order with an equal number of same and different auditory pairs of stimuli. Each session generally consisted of 60 trials. At the conclusion of a session, tokens were traded in for money or edibles such as raisins. Sessions were usually conducted 3-5 times per week, depending on the availability of each participant.
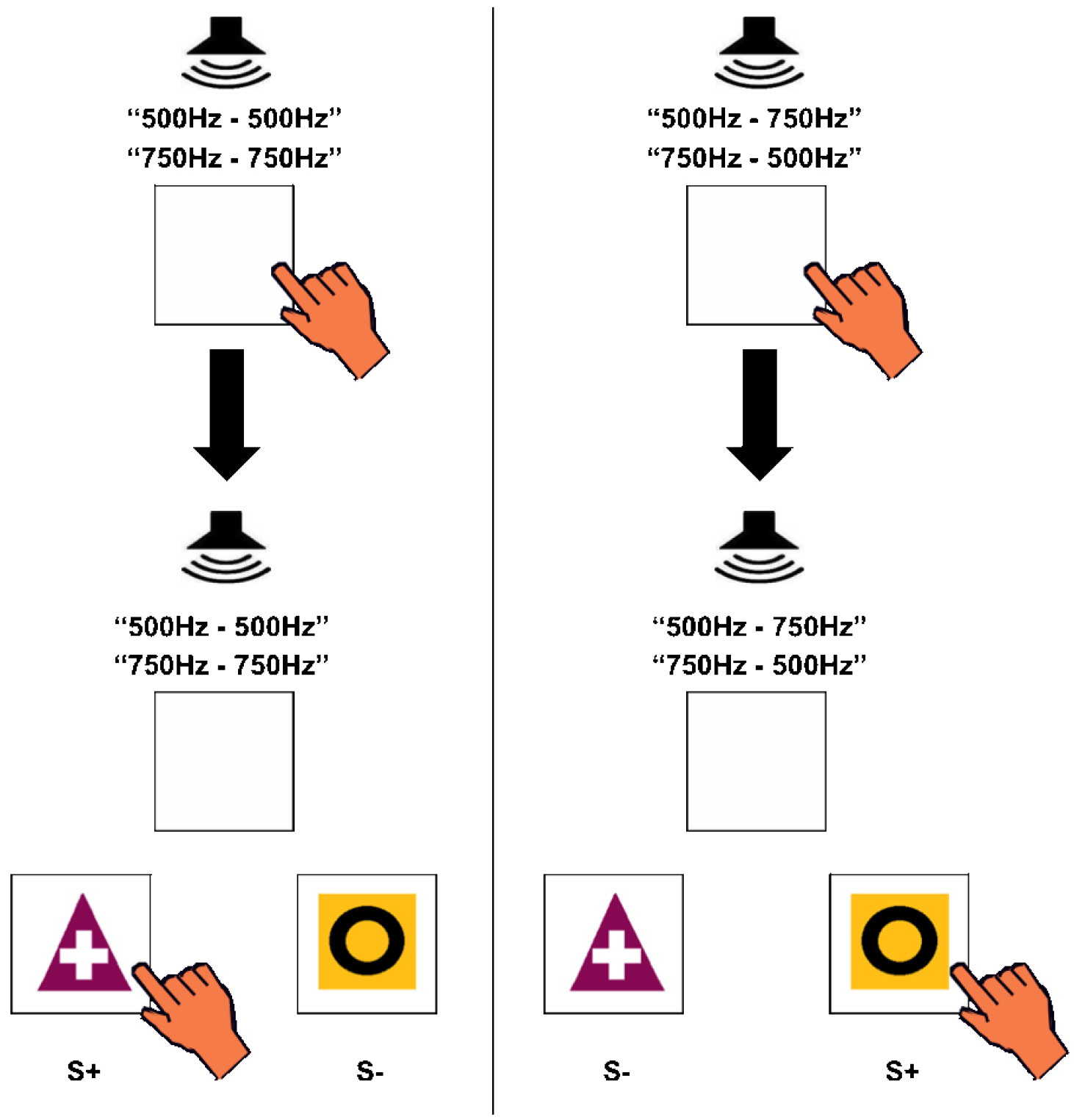

Figure 1. Baseline frequency discrimination task with the same/different, go/no-go procedure. The left panel illustrates "same" trials, either with $750 \mathrm{~Hz}$ or $500 \mathrm{~Hz}$. The right panel illustrates "different" trials. 
Table 1

Gender, Chronological Ages (CA), Peabody Picture Vocabulary Test (PPVT) and Expressive One-Word Picture Vocabulary Test (EOWPVT) scores for study 1 participants

\begin{tabular}{ccccc}
\hline $\begin{array}{c}\text { Participant } \\
\text { code }\end{array}$ & Gender & $\begin{array}{c}\text { CA } \\
\text { (years-months) }\end{array}$ & $\begin{array}{c}\text { PPVT score } \\
\text { (years-months) }\end{array}$ & $\begin{array}{c}\text { EOWVT score } \\
\text { (years-months) }\end{array}$ \\
\hline RSE & F & $19-10$ & $6-01$ & $5-09$ \\
MIB & M & $21-0$ & $6-07$ & $5-06$ \\
EBG & M & $15-0$ & $9-02$ & $8-07$ \\
JAR & M & $14-3$ & $6-08$ & $6-01$ \\
MES & M & $19-5$ & $9-11$ & $13-04$ \\
\hline
\end{tabular}

STUDY 1: SAME/DIFFERENT, “GO-LEFT/ GO-RIGHT" FREQUENCY DISCRIMINATION

Study 1 asked whether participants with intellectual disabilities could readily acquire same/different, "go-left/go-right" performances with minimal prompting and differential reinforcement ("trial and error") in a frequency discrimination task involving two sine-wave tones. As noted earlier, such performance could serve as a useful baseline from which further assessments of auditory discrimination could be developed. The next step in auditory discrimination assessment would be to examine pairs of auditory stimuli that differ from those used to train baseline performance, thereby examining generalized auditory same/different judgments. Therefore, a second question of Study 1 asked whether participants, who could acquire the baseline frequency discrimination task, could also generalize their performance to new auditory stimuli, recorded spoken words. Finally, for participants that could successfully generalize their same/ different performance, Study 1 also examined the feasibility of using this non-verbal procedure to test participants' unreinforced performance in an assessment task assessing sensitivity to different (relatively large and small) tone disparities. Performance with different disparities ultimately could provide evidence about the extent of participants' discrimination abilities as auditory stimuli are made more similar. As described below, these three questions were addressed in three separate experimental phases.

\section{MeTHOD}

\section{Participants}

Five participants, all with intellectual disabilities, were recruited from a local residential school for individuals with developmental disabilities. Each was assigned a code to conceal his/her identity. Table 1 shows their 
Table 2

Baseline and probe-trial auditory stimulus pairs and results for EBG and MIB, Experiment 1, Phase 3

\begin{tabular}{|c|c|c|c|c|c|c|}
\hline & \multirow{2}{*}{\multicolumn{2}{|c|}{ EBG }} & \multirow{2}{*}{\multicolumn{2}{|c|}{ MIB (first assessment) }} & & \\
\hline & & & & & \multicolumn{2}{|c|}{ MIB (second assessment) } \\
\hline & $\begin{array}{l}\text { auditory tone- } \\
\text {-stimulus pairs }\end{array}$ & $\begin{array}{c}\text { accu- } \\
\text { racy }\end{array}$ & $\begin{array}{l}\text { auditory tone- } \\
\text {-stimulus pairs }\end{array}$ & $\begin{array}{c}\text { accu- } \\
\text { racy }\end{array}$ & $\begin{array}{l}\text { auditory tone- } \\
\text {-stimulus pairs }\end{array}$ & $\begin{array}{c}\text { accu- } \\
\text { racy }\end{array}$ \\
\hline \multirow[t]{4}{*}{ Baseline } & $500 \mathrm{~Hz}-500 \mathrm{~Hz}$ & $100 \%$ & $500 \mathrm{~Hz}-500 \mathrm{~Hz}$ & $100 \%$ & $500 \mathrm{~Hz}-500 \mathrm{~Hz}$ & $100 \%$ \\
\hline & $750 \mathrm{~Hz}-750 \mathrm{~Hz}$ & $100 \%$ & $750 \mathrm{~Hz}-750 \mathrm{~Hz}$ & $92 \%$ & $750 \mathrm{~Hz}-750 \mathrm{~Hz}$ & $100 \%$ \\
\hline & $500 \mathrm{~Hz}-750 \mathrm{~Hz}$ & $83 \%$ & $500 \mathrm{~Hz}-750 \mathrm{~Hz}$ & $100 \%$ & $500 \mathrm{~Hz}-750 \mathrm{~Hz}$ & $100 \%$ \\
\hline & $750 \mathrm{~Hz}-500 \mathrm{~Hz}$ & $100 \%$ & $750 \mathrm{~Hz}-500 \mathrm{~Hz}$ & $100 \%$ & $750 \mathrm{~Hz}-500 \mathrm{~Hz}$ & $100 \%$ \\
\hline \multirow[t]{11}{*}{ Probes } & $500 \mathrm{~Hz}-520 \mathrm{~Hz}$ & $92 \%$ & $500 \mathrm{~Hz}-520 \mathrm{~Hz}$ & $83 \%$ & $500 \mathrm{~Hz}-510 \mathrm{~Hz}$ & $75 \%$ \\
\hline & $520 \mathrm{~Hz}-500 \mathrm{~Hz}$ & $92 \%$ & $520 \mathrm{~Hz}-500 \mathrm{~Hz}$ & $92 \%$ & $510 \mathrm{~Hz}-500 \mathrm{~Hz}$ & $83 \%$ \\
\hline & $\underline{520 \mathrm{~Hz}-520 \mathrm{~Hz}}$ & $92 \%$ & $\underline{520 \mathrm{~Hz}-520 \mathrm{~Hz}}$ & $100 \%$ & $\underline{510 \mathrm{~Hz}-510 \mathrm{~Hz}}$ & $100 \%$ \\
\hline & $500 \mathrm{~Hz}-625 \mathrm{~Hz}$ & $100 \%$ & $500 \mathrm{~Hz}-625 \mathrm{~Hz}$ & $100 \%$ & $500 \mathrm{~Hz}-625 \mathrm{~Hz}$ & $100 \%$ \\
\hline & $625 \mathrm{~Hz}-500 \mathrm{~Hz}$ & $100 \%$ & $625 \mathrm{~Hz}-500 \mathrm{~Hz}$ & $100 \%$ & $625 \mathrm{~Hz}-500 \mathrm{~Hz}$ & $100 \%$ \\
\hline & $\underline{625 \mathrm{~Hz}-625 \mathrm{~Hz}}$ & $100 \%$ & $\underline{625 \mathrm{~Hz}-625 \mathrm{~Hz}}$ & $100 \%$ & $\underline{625 \mathrm{~Hz}-625 \mathrm{~Hz}}$ & $92 \%$ \\
\hline & $750 \mathrm{~Hz}-730 \mathrm{~Hz}$ & $92 \%$ & $750 \mathrm{~Hz}-730 \mathrm{~Hz}$ & $8 \%$ & $750 \mathrm{~Hz}-720 \mathrm{~Hz}$ & $67 \%$ \\
\hline & $730 \mathrm{~Hz}-750 \mathrm{~Hz}$ & $83 \%$ & $730 \mathrm{~Hz}-750 \mathrm{~Hz}$ & $0 \%$ & $720 \mathrm{~Hz}-750 \mathrm{~Hz}$ & $75 \%$ \\
\hline & $\underline{730 \mathrm{~Hz}-730 \mathrm{~Hz}}$ & $92 \%$ & $\underline{730 \mathrm{~Hz}-730 \mathrm{~Hz}}$ & $100 \%$ & $\underline{720 \mathrm{~Hz}-720 \mathrm{~Hz}}$ & $100 \%$ \\
\hline & $750 \mathrm{~Hz}-625 \mathrm{~Hz}$ & $100 \%$ & $750 \mathrm{~Hz}-625 \mathrm{~Hz}$ & $92 \%$ & $750 \mathrm{~Hz}-625 \mathrm{~Hz}$ & $100 \%$ \\
\hline & $625 \mathrm{~Hz}-750 \mathrm{~Hz}$ & $100 \%$ & $625 \mathrm{~Hz}-750 \mathrm{~Hz}$ & $92 \%$ & $625 \mathrm{~Hz}-750 \mathrm{~Hz}$ & $83 \%$ \\
\hline
\end{tabular}

chronological ages (CAs) and their receptive and expressive language abilities. Receptive language was measured with the Peabody Picture Vocabulary Test (PPVT - IIIA and 4A; Dunn and Dunn, 1997, 2007). Expressive language was measured with the Expressive One-Word Picture Vocabulary Test (EOWPVT - 2000 Edition; Brownell, 2000). Chronological ages ranged from 14-3 (years-months) to 21-0 years (mean 17-10; median 19-5). Using the PPVT scores, the estimated mental ages ranged from 6-1 to 9-11 (mean 7-8; median 6-8). All participants had normal hearing (+/- $5 \mathrm{~dB} \mathrm{HL})$, as assessed with a pure-tone audiogram prior to their participation. Four of the five participants had served in prior studies involving visual discrimination, but none had experienced the present procedures.

\section{Procedure}

Phase 1: Baseline same/different, "go-left/go-right" training. Each of the five participants was exposed to baseline training of the experimental task with minimal prompting and differential reinforcement. Stimuli consisted of sine-wave tones of $750 \mathrm{~Hz}$ and $500 \mathrm{~Hz}$. Frequencies in this range are similar to those 
in the target range of other auditory studies examining children with disabilities (e.g., Jones et al., 2009). Each tone was $150 \mathrm{~ms}$ in duration. Four two-stimulus pairs were used as samples: $750 \mathrm{~Hz}-750 \mathrm{~Hz}, 500 \mathrm{~Hz}-$ $500 \mathrm{~Hz}$ ("same" trials) and $750 \mathrm{~Hz}-500 \mathrm{~Hz}$, $500 \mathrm{~Hz}-750 \mathrm{~Hz}$ ("different" trials). Each of the four pairs was presented 15 times per session, for a total of 60-trials. For all participants, the auditory stimuli were presented through speakers, and responses were made to a touch-sensitive computer screen. The first experimental session for each participant contained a minimal prompting procedure for the first eight trials, the presentation of only the correct response key after a touch to the center key. For all subsequent trials of the first session and all subsequent sessions, both response keys were present. All participants' correct responses were reinforced. Successful task acquisition was defined as three 60-trial sessions in which overall accuracy was 90\% or higher. Failure to acquire the task was defined as three sessions in which there was no upward or downward trend in accuracy.

Phase 2: Generalization to new auditory stimuli. Participants that acquired the baseline tone discrimination were exposed to training sessions with new auditory stimuli, the spoken words "cat" and "dog," $477 \mathrm{~ms}$ and $577 \mathrm{~ms}$ in duration, respectively. As in the previous phase, four two-stimulus complexes were used:"cat"-“cat", "dog"-"“dog" ("same" trials) and "cat"-“dog", "dog" - "cat” ("different" trials). Successful task acquisition was defined as three 60-trial sessions in which overall accuracy was 90\% or higher.

Phase 3: Auditory stimulus disparity assessment. In Phase 3, participants that demonstrated generalization in Phase 2 were exposed to pairs of tones that differed from those used in the baseline trials of Phase 1. The assessment protocol consisted of three steps: (a) three sessions with the trained baseline same/different, "go-left/go-right" task with $500 \mathrm{~Hz}$ and $750 \mathrm{~Hz}$ stimuli; (b) three sessions of the same baseline task without reinforcement, in preparation for (c) assessment sessions consisting of a random mix of unreinforced baseline auditory stimulus pairs and unreinforced, untrained test pairs of stimuli. Table 2 shows the baseline and experimental probe pairs used in the latter step. The left and center columns represent the baseline and test pairs for EBG's assessment and the first assessment for MIB, respectively. Each test pair was presented four times per session. The full assessment consisted of three sessions. Thus, the participants were exposed to twelve instances of each pair. Based on his performance, a second assessment was conducted with MIB. This assessment was similar to the first, except that some of the frequency values were altered; the altered pairs appear in bold (see the right column of Table 2).

\section{Results}

\section{Phase 1}

Figure 2 shows the results of Experiment 1, Phase 1. Two participants, EBG and MIB, successfully mastered the frequency discrimination task. EBG and MIB each met the learning criterion in five sessions and went on to participate in Phases 2, and 3. JAR, RSE, and MES did not meet the criterion.

\section{Phase 2}

EBG and MIB demonstrated immediate criterion performance with the spoken- 


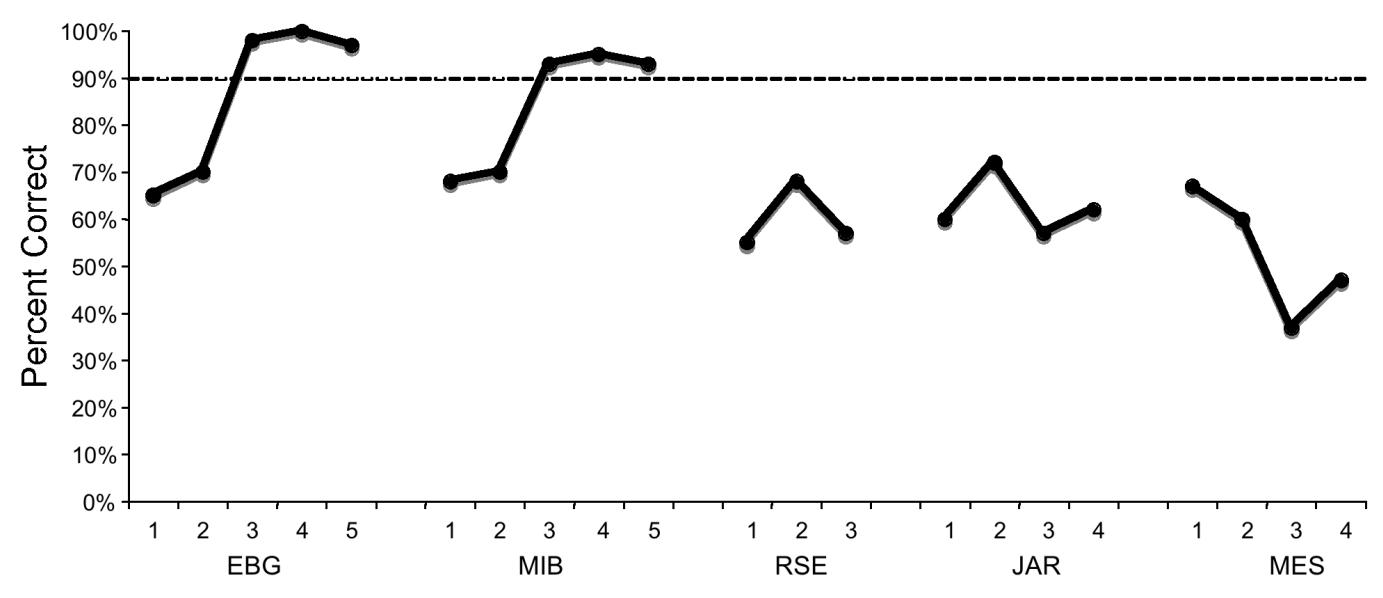

Sessions

Figure 2. Percent correct across sessions in Study 1 for all five participants. The crriterion performance level, 90\% accuracy, is indicated by the dotted line.

-word stimuli. Across three sessions, their accuracy was 100\%, 100\%, and 98\% (EBG) and 98\%, $98 \%$, and $97 \%$ (MIB).

\section{Phase 3}

In the first step, reintroduction of the tone stimuli, both subjects maintained criterion ( $\geq 90 \%)$ accuracy across three sessions. Both participants also maintained criterion accuracy in the second step, unreinforced baseline sessions. The third step consisted of one 3-session assessment for EBG and two 3-session assessments for MIB. Table 2 shows the results. For each participant, each of the four baseline and 11 probe types was presented 12 times across three sessions. As shown in the upper portion of the table, both participants demonstrated nearly perfect mean accuracy on each of the baseline trial types. The lower left portion of the table shows the results of each probe type for EBG. Note that "same" trial pairs are underlined. The remaining "different" pairs represented different tone disparities: a relatively small, $20 \mathrm{~Hz}$ disparity $(500 \mathrm{~Hz}-$ $520 \mathrm{~Hz}$ and $750 \mathrm{~Hz}-730 \mathrm{~Hz}$ ), and a larger, $125 \mathrm{~Hz}$ disparity $(500 \mathrm{~Hz}-625 \mathrm{~Hz}$ and $750 \mathrm{~Hz}-625 \mathrm{~Hz}$ ). EBG showed perfect accuracy when the disparity was large and somewhat lower accuracy when the disparity was small.

During the first assessment for MIB (middle column), he showed nearly perfect accuracy with the large disparity and somewhat lower accuracy with the small disparity programmed at $500 \mathrm{~Hz}$. However, MIB's accuracy with the small disparity at $750 \mathrm{~Hz}$ was extremely low, suggesting that he judged those pairs of stimuli as the same. To test this hypothesis, MIB received a second 3-session assessment (right column, pairs in bold) in which the small disparity at $750 \mathrm{~Hz}$ was made greater $(30 \mathrm{~Hz})$ in an attempt to make it easier to discriminate. At the same time, the small disparity at $500 \mathrm{~Hz}$ on which he performed fairly well was made even smal- 
ler $(10 \mathrm{~Hz})$, a presumably more difficult discrimination. The large disparities remained the same as her first assessment. As expected, MIB showed greater accuracy with the 30 $\mathrm{Hz}$ disparity and somewhat lower accuracy with the $10 \mathrm{~Hz}$ disparity, compared to her first assessment.

\section{DisCUSSION}

In Phase 1, two of the five participants with developmental disabilities readily acquired the auditory same/different, "go-left/go-right" task with minimal prompting. With this task, the two participants demonstrated auditory same/different judgments of sine-wave tones. Importantly, the participants' performance was not dependent on the particular stimuli used to train the task; these participants' also immediately demonstrated highly accurate performance with new stimuli, recorded spoken words, in Phase 2. Thus, across Phases 1 and 2, participants demonstrated generalized auditory same/different judgments, an important prerequisite for using the auditory same/different, "go-left/go-right" task for further assessments.

Phase 3 was a demonstration of the essential features of a non-verbal auditory discrimination assessment: the establishment of a baseline with auditory stimuli from the same dimension as the one that will be assessed; the maintenance of that baseline with no explicit feedback; and then the presentation of unreinforced probe trials mixed with the original baseline. Both participants readily maintained their baseline performance in the absence of reinforcement. Moreover, several aspects of their performance in the latter step of the assessment in the present study contributed to the face validity of the procedure. Specifically, participants maintained high baseline accuracy throughout the probe sessions, indicating that stimulus control by the same/different task remained intact. High accuracy was also maintained with the probe trials in which the two stimuli in the pair were identical. In one sense, the identical probe pairs (see Table 2, underlined probes) functioned as "control" trials; not only would high accuracy be expected (they are relatively easy discriminations to make), but in combination with "different" probes, they helped to rule out alternate sources of stimulus control, such as a position bias. In addition, participants' performance was fairly consistent within probe value; performance was similar whether a given stimulus in a pair was presented first or second in the stimulus complex. Lastly, both participants' performance with "different" probes bolstered the face validity of the procedure. Each demonstrated high accuracy with relatively large disparities, but somewhat lower accuracy with relatively small disparities. This was particularly true with MIB's first assessment, in which he largely regarded the probes with a $20 \mathrm{~Hz}$ disparity at $750 \mathrm{~Hz}$ as the same (i.e., apparently he could not tell the difference between them). The increased disparity in the second assessment, and MIB's improved performance, lends further credence to the face validity of the assessment. Interestingly, though MIB regarded the probes in the first assessment with a $20 \mathrm{~Hz}$ disparity at $500 \mathrm{~Hz}$ as the same, this was not true for probes with a $20 \mathrm{~Hz}$ disparity at $750 \mathrm{~Hz}$. This performance appears consistent with an application of Fechner-Weber's Law (Fechner, 1860/1912) to the subjective perception of $20 \mathrm{~Hz}$ dispa- 
rities at $750 \mathrm{~Hz}$ vs. $500 \mathrm{~Hz}$. That is, humans would perceive a $20 \mathrm{~Hz}$ disparity at $750 \mathrm{~Hz}$ as less than a $20 \mathrm{~Hz}$ disparity at $500 \mathrm{~Hz}$ (Stevens, Volkman, \& Newman, 1937). This perceptual difference may account for $750 \mathrm{~Hz}$ vs. $730 \mathrm{~Hz}$ being a more difficult discrimination for MIB. Nevertheless, given his lowered accuracy when the disparity was changed to $10 \mathrm{~Hz}$ in the second assessment as well as his maintenance of high accuracy on baseline and "same" probes, there is no reason to suspect that any general feature of the assessment was responsible for this performance, other than the particular stimulus frequency values.

Taken together, it appears that the results of the two participants who completed all three phases of Study 1 support the feasibility of using the auditory "go-left/go-right" task as a general-purpose, nonverbal auditory assessment of same/different judgments with individuals with developmental disabilities.

Study 2: Stimulus-CONTROL SHAPING METHODS FOR ESTABLISHING A TONE DISCRIMINATION

Though successful in many respects, Study 1 proved limited in another: Only two of the five participants readily acquired the tone-discrimination task. Given the few participants available for study, one cannot readily surmise from Study 1 the percentage of a larger population of participants with similar levels of disability that would readily acquire the task with minimal prompting. Therefore, it is important to explore alternative methods for establishing the task with participants who do not readily acquire it without special training. This was the focus of Study 2; the aim was to develop same/different judgments of different tone frequencies.

In an informal follow-up investigation, two of the three participants that did not acquire the tone discrimination in Study 1, RSE and JAR, eventually were able to demonstrate the auditory same/different, "go-left/go-right" task with the spoken words, "dog" and "cat." Further, RSE and JAR demonstrated generalization to new words, "tree" and "house." MES was unable to perform the task with either set of words, and his participation ended. For RSE and JAR, their performance with words was not a sufficient prerequisite for demonstrating subsequent same/different judgments with tone stimuli, even when the disparity between the stimuli was very large: 1,250 Hz. Therefore, Study 2 asked whether a superimposition and fading method (Etzel \& LeBlanc, 1979; Terrace, 1963), known to be successful with many participants with intellectual disabilities when learning visual discriminations, would prove feasible in transferring stimulus control by spoken words to tones. Unfortunately, JAR was unable to continue participation due to behavior problems. Hence, Study 2 examined stimulus control transfer with RSE and a naive participant with intellectual disabilities.

\section{METHOD}

\section{Participants, apparatus, setting}

Two participants served: RSE from Study 1 and a naïve participant, RBW. RBW was a female with a CA of 18-9 and an estimated mental age (PPVT results) of 6-8. An expressive language test was not administered. RBW attended a day school program for individuals with intellectual disabilities. 
The apparatus was the same as Study 1, except that RSE's responses were recorded by a touch-sensitive monitor, while RBW responded using a mouse. In addition, stimuli were presented through speakers with RSE and through headphones with RBW. The study setting was the same as in Study 1.

\section{Stimuli}

The baseline stimuli for RSE were the recorded spoken words, "tree" and "house"; her target-discrimination stimuli were sine-wave tones, $250 \mathrm{~Hz}$ and 1,500 Hz. During superimposition (see below), the $250 \mathrm{~Hz}$ tone was superimposed on "tree" and the 1,500 Hz tone was superimposed on "house." Each tone was matched in duration to their respective words $(250 \mathrm{~Hz}=592 \mathrm{~ms} ; 1500$ $=772 \mathrm{~ms}$ ). The baseline stimuli for RBW were the recorded spoken words, "dog" and "cat"; her target discrimination stimuli were sine-wave tones, $2,500 \mathrm{~Hz}$ (superimposed on “dog," $577 \mathrm{~ms}$ ) and 3,500 Hz (superimposed on "cat," $477 \mathrm{~ms})$.

\section{Pre-study performance}

Each participant entered Study 2 with highly accurate same/different judgments of recorded spoken words, which were established via a variety of stimulus control shaping methods. However, each participant demonstrated low-accuracy same/different judgments of their respective tone stimuli (RSE: 60\% across two prompted sessions; RBW: 44\% across four unprompted sessions).

\section{Procedure}

Superimposition and fading. In general, the superimposition-and-fading protocol consisted of six stages; criterion performance $(\geq 90 \%$ accuracy) was required to move from one stage to the next. In the first stage, the words were presented alone. In the second stage, the words were presented at $100 \%$ intensity, while the tones were gradually faded onto the words in 8 steps of increasing intensity, from $0 \%$ to $100 \%$. In the third stage, both words and tones were presented at equal (100\%) intensity. In the fourth stage, the tones remained at $100 \%$ intensity, while words were faded out in 8 steps of decreasing intensity, from 100\% to $0 \%$. In the fifth stage, only the tones at $100 \%$ intensity were presented, but with their respective durations, as used during the previous fading stages. Finally, in the sixth stage, to ensure that responses were being made on the basis of frequency and not stimulus duration, all tone durations were standardized as follows: $150 \mathrm{~ms}$ for RBW and $500 \mathrm{~ms}$ for RSE. For both participants, fading-in and fading-out auditory stimuli followed a titrating progression. That is, in a block of four trials (two trials where the stimuli were the same and two trials where the stimuli were different), correctly responding to all four resulted in a progression to the next fading step; a single error in the block resulted in the presentation of the previous intensity-fading step. Based on RSE's performance, several modifications were made to the fourth stage, fading out the words, as shown in Table 4. The number of trials per session varied from 40 to 62 for both participants.

\section{RESULTS AND DISCUSSION}

Tables 3 and 4 show the results for RBW and RSE, respectively. As shown in Table 3, RBW required only a single session to meet criterion for the first three stages. In the 
Table 3

Auditory superimposition-and-fading protocol stage and results for RBW

\begin{tabular}{clc}
\hline Session number & \multicolumn{1}{c}{ Protocol stage } & $\begin{array}{c}\text { Session } \\
\text { accuracy in percent }\end{array}$ \\
\hline 1 & words only & 100 \\
2 & fade-in tones & 100 \\
3 & words and tones & 100 \\
4 & fade-out words & $86^{\mathrm{a}, \mathrm{b}}$ \\
5 & final performance: tones only, standardized at & 100 \\
& 150 ms & 100 \\
\hline
\end{tabular}

${ }^{a}$ Last fading step accuracy in percent.

b $100 \%$ accuracy on the last 19 trials.

Table 4

Auditory superimposition-and-fading protocol stage and results for RSE

\begin{tabular}{clc}
\hline $\begin{array}{c}\text { Session } \\
\text { number }\end{array}$ & \multicolumn{1}{c}{ Protocol stage } & $\begin{array}{c}\text { Session accuracy } \\
\text { in percent }\end{array}$ \\
\hline 1 & words only & 100 \\
2 & fade-in tones & 100 \\
3 & words and tones & 100 \\
4 & fade-out words & $55^{\mathrm{a}}$ \\
5 & words and tones & 100 \\
6 & words and tones & 98 \\
7 & fade-out words $100 \%$ to $13 \%$ intensity & $100^{\mathrm{a}}$ \\
8 & words (13\% intensity) and tones (100\% intensity) & 100 \\
9 & fade-out words $(13 \%, 11 \%, 10 \%, 8 \%, 7 \%, 5 \%, 4 \%, 2 \%, 0 \%)$ & $29^{\mathrm{a}}$ \\
10 & fade-out words $(13 \%, 11 \%, 10 \%, 8 \%, 7 \%, 5 \%, 4 \%, 2 \%, 0 \%)$ & $67^{\mathrm{a}}$ \\
11 & fade-out words 13\% to 5\% intensity & $100^{\mathrm{a}}$
\end{tabular}


Continued

\begin{tabular}{clc}
\hline $\begin{array}{c}\text { Session } \\
\text { number }\end{array}$ & \multicolumn{1}{c}{ Protocol stage } & $\begin{array}{c}\text { Session Accuracy } \\
\text { in Percent }\end{array}$ \\
\hline 12 & words (5\% intensity) and tones (100\% intensity) & 100 \\
13 & fade-out words $(5 \%, 4 \%, 3 \%, 2 \%, 1 \%, 0 \%)$ & $89^{\mathrm{a}}$ \\
14 & fade-out words $(5 \%, 4 \%, 3 \%, 2 \%, 1 \%, 0 \%)$ & $89^{\mathrm{a}}$ \\
15 & fade-out words $(5 \%, 4 \%, 3 \%, 2 \%, 1 \%, 0 \%)$ & $93^{\mathrm{a}}$ \\
16 & fade-out words $(3 \%, 2 \%, 1 \%, 0 \%)$ & $91^{\mathrm{a}}$ \\
17 & fade-out words $(3 \%, 2 \%, 1 \%, 0 \%)$ & $100^{\mathrm{a}}$ \\
18 & final performance: tones only & 100 \\
19 & final performance: tones only & 69 \\
20 & final performance: tones only & 94 \\
21 & final performance: tones only, standardized at $500 \mathrm{~ms}$ & 92 \\
22 & final performance: tones only, standardized at $500 \mathrm{~ms}$ & 98 \\
23 & final performance: tones only, standardized at $500 \mathrm{~ms}$ & 90 \\
\hline
\end{tabular}

${ }^{a}$ Last fading step accuracy in percent.

fourth session, the words were faded out. However, RBW showed only 86\% accuracy when the words were no longer present. $\mathrm{Ne}-$ vertheless, of the 28 trials at that final step, RBW's responses were correct for the last 19 consecutive trials. Therefore, she progressed to the final stage, in which the stimulus durations were standardized at $150 \mathrm{~ms}$ (Sessions 5 and 6), and showed 100\% accuracy.

Like RBW, RSE (see Table 4) required only a single session for each of the first three stages, but RSE required many more sessions to complete the protocol. For example, in Session 4, RSE did not meet criterion on the final fading step. In Sessions 5 and 6, her previously accurate word-and-tone performance recovered. In Session 7, the fading steps were modified such that the tones remained at $100 \%$, but the words faded out only to $13 \%$ intensity; she performed with high accuracy. In Session 8, RSE maintained the superimposition of $100 \%$-intensity tones with $13 \%$-intensity words at high accuracy. In Sessions 9 and 10, a new set of fading steps was introduced in an attempt to fade the intensity of the words more slowly, from 13\% to $0 \%$. However, RSE still could not meet criterion when the tones were presented alone. In Session 11, the fading steps were again modified such that the tones remained at $100 \%$, but the words faded out from $13 \%$ intensity to $5 \%$; she performed with high accuracy. In Session 12, she maintained high accuracy when the entire session consisted 
of words at 5\% intensity and tones at $100 \%$ intensity. In Sessions 13-17, attempts were again made to fade the words even more slowly; RSE's accuracy improved. In Sessions 18-20, RSE showed highly accurate performance with only the tones for two of the three sessions. It is unclear why RSE's performance was poor during Session 19. Nevertheless, when the durations for each of the tone stimuli were standardized at $500 \mathrm{~ms}$ (Sessions 20-23), RSE met criterion, indicating that she had learned the tone discrimination with the task.

In sum, both participants showed transfer of stimulus control within the same/ different, "go-left/go-right" task from auditory stimuli that they could discriminate (spoken words) to auditory stimuli they could not discriminate (tones) via a superimposition-and-fading procedure. Though RBW progressed through the protocol rapidly, RSE required several modifications to the protocol until she was able to demonstrate performance required by criterion with the tone stimuli. Nevertheless, Study 2 demonstrated a successful procedure for participants who did not readily acquire tone discriminations with minimal prompting.

\section{GENERAL DISCUSSION}

In Study 1, two of five participants with intellectual disabilities readily acquired an auditory same/different, "go-left/go-right" discrimination task with sine-wave tone stimuli. These two participants immediately generalized their performance to recorded spoken words. Finally, the two participants successfully demonstrated face-value perfor- mance in a rudimentary auditory assessment task with tone stimuli. For participants who entered Study 2 with extant discrimination of spoken words, it was demonstrated that tone discrimination in the task could be established via a superimposition-and-fading method. Together, the two studies provide support for the feasibility and potential utility of the "go-left/go-right" task for further development as an auditory assessment procedure. To our knowledge, this is the first demonstration of an entirely nonverbal task that can be used to evaluate same/different judgments of single pairs of successively presented auditory stimuli with individuals with intellectual disabilities.

This demonstration extends previous auditory discrimination methods in important ways. First, as noted earlier, the present "go-left/go-right" task requires a response on every trial. Thus, the present task does not preclude use by participants with intellectual disabilities or any other participant that may have difficulty refraining from responding, as would be required in a go/no-go task. Also, consider the more traditional matching-to-sample format of the "go-left/go-right" task used by Serna et al. (1996): The participants were required to respond to the left key, given one auditory sample stimulus, and to the right key given the other auditory sample stimulus. Though technically the two auditory stimuli were presented successively, a response requirement and an ITI intervened between the presentations of the auditory stimuli. It would not be unreasonable to assume that the interval between the two auditory stimuli (at least several seconds) could present difficulties for participants with intellectual challenges. The traditional 
matching format would likely present other problems. For example, participants would require separate sample-left and sample-right training for each and every auditory stimulus pair of experimental interest. That is, the single-sample go-left/go-right format does not lend itself to generalized performance. This method would be a very cumbersome way to assess discrimination. Similar issues would be present using the auditory matching task from Dube, Green, and Serna (1993) for same/different assessment purposes. In their task, each trial consisted of the presentation of an auditory sample followed by one auditory comparison, then a second presentation of the same auditory sample followed by the second comparison. Normally capable adult participants indicated that one or the other sample/comparison presentation was related (by reflexivity, symmetry or transitivity) by selecting one of two concurrently available gray rectangles positioned in the upper left or right of the computer screen. Each rectangle had been experimentally associated with either the first or second auditory sample/ comparison set during the trial. The procedure proved to be excellent for examining stimulus equivalence class formation (Sidman, 1971; Sidman \& Tailby, 1982) in which all stimuli were auditory. However, like the Serna et al. (1996) procedure, the memory requirements are greater than might be possible for a participant with intellectual disabilities. Further, as an assessment procedure, perhaps to test discrimination of decreasing disparity between tone stimuli, use of the Dube et al. (1993) would present challenges. For example, suppose one sought to determine whether participants judged two similar frequencies, 3,000 $\mathrm{Hz}$ and 2,920 Hz, as the same or different. Stimulus $3,000 \mathrm{~Hz}$ might be played as a sample stimulus with $2,920 \mathrm{~Hz}$ as a comparison. But what would be used as the other comparison? One possibility would be to present a tone that is very different from the sample, such as $1,000 \mathrm{~Hz}$. However, should a participant select the $2,920 \mathrm{~Hz}$ tone in this context, we would know only that s/he judges $3,000 \mathrm{~Hz}$ and $2,920 \mathrm{~Hz}$ as more similar to one another than $3,000 \mathrm{~Hz}$ and $1,000 \mathrm{~Hz}$; we would not know whether s/he judges $3,000 \mathrm{~Hz}$ and $2,920 \mathrm{~Hz}$ as the same, that is, as an undetectable difference. In sum, these issues are not problems in the present procedure; the auditory stimuli are presented in relatively rapid succession, that is, as a pair in which the stimuli are separated only by $500 \mathrm{~ms}$. Only a single response is required to indicate a same/different judgment per pair of stimuli, another result of which is a relatively efficient procedure.

The findings from the present study raise new questions. Most studies in auditory discrimination or perception with individuals with autism (e.g., Bonnel et al., 2003), focus on populations that are "high-functioning," and therefore require participants with high levels of receptive language to understand relatively complex instructions. A nonverbal task does not require such levels. Indeed, the participants in the present study would be considered "lower functioning," even though they all had some language skills. Though is not the focus here, it is unknown whether the participants might have been able to express in simple verbal terms whether they regarded the pairs of stimuli as same or different. However, in a study involving a yes/ no visual-discrimination task, analogous to the procedures used here, Serna, Oross, and 
Murphy (1998) found that one verbal participant with intellectual disabilities (CA 1810 ; estimated mental age 7-6; similar in functioning ability to those in the present study) was unable to complete a verbal-response version of the task, but had no difficulty completing a nonverbal version of the task. This finding suggests that even for individuals whose functioning level permits them to make verbal responses, a nonverbal task, such as the present one, may be more practical. Of course, a formal study that examines this question is needed before any firm conclusions can be drawn.

The present study also raises concerns about the generality of the findings to other individuals with intellectual disabilities. Only two of the initial five participants readily acquired the task with tone discriminations in Study 1. However, two additional participants (RSE and JAR) had acquired word discriminations in informal follow-up investigation. In Study 2, RSE and a naïve participant, RBW, eventually acquired the tone discrimination in the "go-left/go-right" task via a stimulus control shaping method. More in-depth manipulations are needed before one can assert that the present method is reliable. For example, unaddressed in the present study is the extent to which participants who undergo prolonged stimulus-control shaping programming to establish a tone discrimination will generalize their performance to other pairs of stimuli that are of interest to experimenters. Neither RSE or RBW were available for extended generalization testing, but in a brief, informal follow-up investigation, their performance did not always indicate accurate generalization. Nevertheless, a study with a larger group of participants, perhaps including several groups of graded functioning levels, would help address this question. For participants who do not acquire the task with any auditory stimuli (e.g., MES in the present study), methods for establishing the first instances of generalized conditional auditory stimulus-stimulus relations based on identity need to be further researched.

Finally, should additional research in this area ultimately result in a very reliable and general-purpose auditory assessment procedure, there are several ways the task could be used. For example, the procedure may be useful for assessing psychophysical performance with a variety of auditory stimuli; one could easily envision testing a more extensive set of graded-disparity pairs such that a pitch discrimination threshold could be determined. Other prosodic characteristics of speech could be assessed as well. More generally, the assessment could be used to verify the discriminability of auditory stimuli prior to their use in an auditory-visual matching to sample task. Of course, one would need an additional procedure to verify the discriminability when they are separated in time, as is the case in most auditory-visual matching tasks. Nevertheless, the assessment task could ultimately play a significant role in understanding more fully the reasons that auditory learning sometimes fails to occur.

\section{REFERENCES}

Abbeduto, L., Furman, L., \& Davies, B. (1989). Relation between the receptive language and mental age of persons with mental retardation. American Journal on Mental Retardation, 93, 535-543.

Barker-Collo, S., Jamieson, J., \& Boo, F. (1995) Assessment of Basic Learning Abilities test: Predic- 
tion of communication ability in persons with developmental disabilities. International Journal of Practical Approaches to Disability, 19, 23-28.

Bonnel, A., Mottron, L., Peretz, I, Trudel, M. Gallun, E., \& Bonnel, A. (2003). Enhanced pitch sensitivity in individuals with autism: A signal detection analysis. Journal of Cognitive Neuroscience, 15(2), 226-235.

Brownell, R. (2000). Expressive One-Word Picture Vocabulary Test-2000 Edition. Novato, CA: Academic Therapy Publications.

Chapman, R. S., Schwartz, S. E., \& Kay-Raining Bird, E. (1991). Language skills of children and adolescents with Down syndrome: I. Comprehension. Journal of Speech and Hearing Research, 34, 1106-1120.

D’Amato, M. R., \& Colombo, M. (1985). Auditory matching-to-sample in monkeys (Cebus apella). Animal Learning and Behavior, 13, 375-382.

D'Amato, M. R., \& Worsham, R. W. (1974). Retrieval cues and short-term memory in capuchin monkeys. Journal of Comparative and Physiological Psychology, 86, 274-282.

Dube, W. V. (1991). Computer software for stimulus control research with Macintosh computers. Experimental Analysis of Human Behavior Bulletin, 9, 28-30.

Dube, W. V., Green, G., \& Serna, R.W. (1993). Auditory successive conditional discrimination and auditory stimulus equivalence classes. Journal of the Experimental Analysis of Behavior, 59, 103-114.

Dube, W. V. \& Hiris, E. J. (1999). MTS v 11.6.7 Documentation [Computer software manual]. Waltham, MA: E. K. Shriver Center.

Dube, W. V., Lombard, K. M., Farren, K. M., Flusser, D. S., Balsamo, L. M., Fowler, T. R., \& Tomanari, G. Y. (2003). Stimulus overselectivity and observing behavior in individuals with mental retardation. In R. Cook, K. Murata-Soraci, \& S. Soraci (Eds.). Perspectives on Fundamental Processes in Intellectual Functioning:Vol. 2. Visual information processing: Implications for understanding individual differences (pp. 109-123). Stamford, CT: Ablex.

Dunn, L. M., \& Dunn, L. M. (1997). Peabody Picture Vocabulary Test. (3rd ed.). Circle Pines, MN: American Guidance Service, Inc.

Dunn, L. M., \& Dunn, D. M. (2007). Peabody Picture Vocabulary Test. (4rd ed.). Minneapolis, MN: NCS Pearson, Inc.

Etzel, B. C., \& LeBlanc, J. M. (1979). The simplest treatment alternative: The law of parsimony applied to choosing appropriate instructional control and errorless-learning procedures for the difficult-to-teach child. Journal of Autism and Developmental Disorders, 9, 361-382.

Fechner, G. T. (1860/1912). Elements of psychophysics: Sections VII and XVI (H. S. Langfeld, Trans.). In Rand, B. (Ed.) (1912). The Classical Psychologists (pp. 562-572). Boston: Houghton Mifflin.

Green, G. (1990). Differences in development of visual and auditory-visual equivalence relations. American Journal on Mental Retardation, 95, 260-270.

Jones, C. R. G., Happé, F., Baird, G., Simonoff, E., Marsden, A. J. S., Tregay, J., Phillips, R. J., ... Charman, T. (2009). Auditory discrimination and auditory sensory behaviours in autism spectrum disorders. Neuropsychologia, 47, 2850-2858.

Klinger, L., Dawson, G., \& Renner, P. (2002). Autistic disorder. In E. Mash \& R Barkley (Eds.). Child psychopathology (2nd ed., pp. 409-454). New York: Guilford Press.

McIlvane, W. J., \& Dube,W. V. (1992). Stimulus control shaping and stimulus control topographies. The Behavior Analyst, 15, 89-94.

McIlvane,W. J. \& Dube,W. V. (2003). Stimulus control topography coherence theory: Foundations and extensions. The Behavior Analyst, 26, 195-213.

McIlvane,W. J., Serna, R.W., Dube,W. V., \& Stromer, R. (2000). Stimulus control topography cohe- 
rence and stimulus equivalence: Reconciling test outcomes with theory. In J. Leslie \& D. E. Blackman (Eds.). Issues in experimental and applied analyses of human behavior (pp. 85-110). Context Press: Reno.

McIlvane,W.J., \& Stoddard, L.T. (1981).Acquisition of matching-to-sample performances in severe mental retardation: Learning by exclusion. Journal of Mental Deficiency Research, 25, 33-48.

McIlvane, W. J., \& Stoddard, L. T. (1985). Complex stimulus relations and exclusion in mental retardation. Analysis and Intervention in Developmental Disabilities, 5, 307-321.

Meyerson, L., \& Kerr, N. (1977). Teaching auditory discriminations to severely retarded children. Rehabilitation Psychology, 24 (Monograph Issue), 123-128.

Miller, J. F. (1987). Language and communication characteristics of children with Down syndrome. In A. Crocker, S. Pueschel, J. Rynders, \& C. Tinghey (Eds.). Down syndrome: State of the art (pp. 233-262). Baltimore: Brooks.

Moore, B. C. J. (1973). Frequency difference limens for short-duration tones. The Journal of the Acoustical Society of America, 54(3), 610-619.

Schreibman, L., Charlop, M. H., \& Koegel, R. L. (1982). Teaching autistic children to use extrastimulus prompts. Journal of Experimental Child Psychology, 33, 475-491.

Schreibman, L., Kohlenberg, B. S., \& Britten, K. R. (1986). Differential responding to content and intonation components of a complex auditory stimulus by nonverbal and verbal autistic children. Analysis and Intervention in Developmental Disabilities, 6, 109-125.

Serna, R. W., Jeffery, J. A., \& Stoddard, L. T. (1996) Establishing go-left/go-right auditory discrimination baselines in an individual with severe mental retardation. The Experimental Analysis of Human Behavior Bulletin, 14, 18-23.
Serna, R. W., Oross, S., \& Murphy, N. A. (1998). Nonverbal assessment of line-orientation in individuals with mental retardation. The Experimental Analysis of Human Behavior Bulletin, 16, 13-15.

Serna, R. W., Stoddard, L. T., \& McIlvane, W. J. (1992). Developing auditory stimulus control: A note on methodology. Journal of Behavioral Education, 2, 391-403.

Serna, R. W., Wilkinson, K. M., \& McIlvane, W. J. (1998). Blank-comparison assessment of stimulus-stimulus relations in individuals with mental retardation. American Journal on Mental Retardation, 103, 60-74.

Sidman, M. (1971). Reading and auditory-visual equivalences. Journal of Speech and Hearing Research, 14, 5-13.

Sidman, M., \& Tailby, W. (1982). Conditional discrimination vs. matching-to-sample: An expansion of the testing paradigm. Journal of the Experimental Analysis of Behavior, 37, 5-22.

Stevens, S. S.;Volkman; J.; \& Newman, E. (1937). A scale for the measurement of the psychological magnitude of pitch. Journal of the Acoustical Society of America, 8(3), 185-190.

Stoddard, L.T. (1982). An investigation of automated methods for teaching severely retarded individuals. In N. R. Ellis (Ed.). International review of research in mental retardation (pp. 163-207). New York: Academic Press.

Stoddard, L. T., \& McIlvane, W. J. (1989). Establishing control by spoken words with profoundly mentally retarded individuals. Research in Developmental Disabilities, 10, 141-151.

Terrace, H. S. (1963). Errorless transfer of a discrimination across two continua. Journal of the Experimental Analysis of Behavior, 6, 223-232.

Vause, T., Martin, G. L., \& Yu, D. C. T. (2000) ABLA test performance, auditory matching, and communication ability. Journal on Developmental Disabilities, 7, 123-141. 
A Sociedade Brasileira de Psicologia e a Federação Ibero-americana de Associações de Psicologia tem a satisfação de convidar a comunidade de pesquisadores brasileiros e ibero-americanos para a 42를 Reunião Anual da Sociedade Brasileira de Psicologia \& VIII Congresso Ibero-americano de Psicologia da FIAP, evento que ocorrerá de 17 a 20 de outubro de 2012 no Sheraton São Paulo WTC Hotel, em São Paulo - SP.

\section{CURSOS OFERECIDOS}

- Funciones y disfunciones de las emociones desde una perspectiva evolucionista. Francisco Palmero, Universitat Jaume I de Castellón (España).

- A utilidade das variáveis psicológicas positivas para intervenção em saúde. José Luís Pais Ribeiro, Presidente da Sociedade Portuguesa de Psicologia da Saúde do Porto, Portugal.

- Entrevista Forense para avaliar suspeita de abuso sexual em crianças: o Protocolo NICHD. Carlos Eduardo Peixoto, Instituto Nacional de Medicina Legal, Portugal.

- Quando o Relacionamento Amoroso vai ao Consultório do Psicólogo, Ailton Amélio Silva, Universidade de São Paulo.

- Avaliação de treinamento, desenvolvimento \& educação. Jairo Eduardo Borges-Andrade. Universidade de Brasília.

- Masculinidades e práticas de saúde: Uma abordagem psicossocial. Zeidi Araujo Trindade e Luiz Gustavo Silva Souza, Universidade Federal do Espírito Santo.

- A criança e o Direito: Trauma, memória e envolvimento legal. Gail Goodman, Universidade da Califórnia.

- Bases Evolutivas do Comportamento Humano. Briseida Dogo de Resende e Patricia Izar, Universidade de São Paulo.

- Relação terapêutica: contribuições da pesquisa e da prática clínica. Roberto Banaco, Pontifícia Universidade Católica e Denis Roberto Zamignani, Núcleo Paradigma.

- Propostas educacionais de Douglas Greer. Sergio Luna, Pontifícia Universidade Católica

- O estudo da mente: Considerações epistemológicas a partir de uma perspectiva internacional. Antonio Roazzi, Universidade Federal de Pernambuco.

- O Modelo dos Cinco Grandes Fatores de Personalidade: História, Instrumentos Validados para uso no Brasil e Aplicações. Claudio Hutz, Universidade Federal do Rio Grande do Sul.

- Desenvolvimento Sensorio-Perceptual: Fundamentos, Medidas e aplicações em pesquisa e na clínica psicológica. Marcelo Fernandes Costa, Universidade de São Paulo.

- Psicologia Pediátrica. Maria Aparecida Crepaldi, Universidade Federal de Santa Catarina.

- A identificação e a intervenção precoces no autismo: Estudos e propostas. Carolina Lampréia, Pontifícia Universidade Católica do Rio de Janeiro.

- Subsídios teórico-práticos para avaliação e intervenção psicológica em casos de violência sexual contra crianças e adolescentes. Luísa Habigzang, Universidade Federal do Rio Grande do Sul.

- Psicologia do Esporte. Simone Sanches, Universidade Paulista de Campinas.

- Prevenção e promoção de saúde no quadro da vulnerabilidade e direitos humanos. Vera Paiva, Universidade de São Paulo e Maria Cristina Antunes, Universidade Tuiuti do Paraná.

- Prevenção primordial da violência doméstica contra crianças e adolescentes (VDCA): Da pesquisa à prática. Maria Amélia Azevedo, Universidade de São Paulo.

- Psicologia e políticas sociais. Oswaldo Yamamoto e Isabel Fernandes de Oliveira, Universidade Federal do Rio Grande do Norte.

- Desempenho escolar e consequências da exposição à violência na infância. Julia da Silva, American Psychological Association.

- As inovações na utilização da Terapia do Esquema. Ricardo Wainer, Pontifícia Universidade Católica do Rio Grande do Sul.

- Análise de controle de estímulos em estudos recentes do comportamento de escolha com macacos-prego. Olavo Galvão, Universidade Federal do Pará.

- Psicometria: Questões de epistemologia e de práxis. Luis Pasquali, Universidade de Brasília.

- Fantasias e fantasias inconscientes: Freud, Klein e Lacan. Luiz Claudio Figueiredo, Pontifícia Universidade Católica de São Paulo e Débora Nemer Pinheiro, Universidade Positivo de São Paulo. 